\begin{tabular}{|c|c|}
\hline PORT SAID ENGINEERING RESEARCH JOURNAL \\
Faculty of Engineering - Port Said University \\
Volume 17 No. 2 September 2013 pp:96 - 104
\end{tabular}

\title{
Jeddah CORS/ VRS: Design, Establishment, and Testing
}

\author{
AshrafE. Mousa ${ }^{1}$, Ahmed I. Elhattab ${ }^{2}$ and Suhail A. Elmadani ${ }^{3}$
}

\begin{abstract}
Geodetic infrastructure traditionally consisted of physical (passive) geodetic marks in the ground and the associated data, including coordinates and datum. Over the past two decades, there has been a move away from providing passive geodetic marks to providing active control networks via Continuously Operating GNSS Reference Station (CORS) networks. Continuously Operating Reference System (CORS) is one of the hot developments of GNSS at present. Its appearance has brought profound change to the surveying and mapping industry, and many cities and regions all over the world have built several CORS systems now. Jeddah Municipality (JM) established a Virtual Reference Stations (VRS) GPS network for different survey applications. JM provides the users with VRS service to enable them to reach a real time cm-accuracy of horizontal position with single GPS receiver. This paper introduces Jeddah CORS/VRS design, establishment as well as its assessment using static and Real Time Kinematic (RTK) methods. The results indicate that, Jeddah CORS/VRS complies with the design requirements and can provide centimetre level positioning services.
\end{abstract}

\section{INTRODUCTION:}

The backbone of any modern geodetic reference frame defined by a national geodetic agency is a network of Continuously Operating Reference Stations (CORS). These stations are permanently occupied by Global Navigation Satellite System (GNSS) equipment and the data is processed so that the national geodetic agency can monitor the datum stability. Coordinates can be calculated at almost any desired frequency and regular coordinate updates may be published to reflect changes due to deformation.

There is various size RTK test networks (CORS/VRS) established at different locations worldwide and it is mainly affected by its geographic locations, infrastructure and type of receivers used. Some good examples of such networks are: St. Lawrence River and Southeastern Brazil Tests [Lachapelle et al. 2001], Southern Finland Test [Santala et al. 2002], and Sydnet Project Test [Kinlyside 2006]. The establishment of conventional and RTK CORS networks has opened a new era worldwide [Bock et al. 2002; Rizos 2007; GrejnerBrzezinska et al. 2007].

CORS, as active control, have a number of advantages over traditional passive control, which has made them widely adopted as countries modernise their geodetic infrastructure. Some of these advantages include [e.g. Blick and Donnelly, 2012]:

- Continuous monitoring of crustal deformation.

- (important in tectonically active regions).

- Ability to separate deformation modes, such as long-term deformation from seasonal effects.

Ability to calculate immediately coordinates variation in case of an earthquake or other Contribution in near real-time hazard monitoring deformation event.

\footnotetext{
${ }^{I}$ National Research in stitute of Astronomy and Geophysics, Helwan, Cairo, Egypt.

${ }^{2}$ Faculty of Engineering, Port Said University, Port Said, Egypt

${ }^{3}$ Jeddah Municipality, Jeddah, KSA.
}

- Realisation of international reference frame, which increases the accuracy of positioning.

- GNSS users need only one receiver to obtain a centimetre-accurate position, anywhere within the network coverage area.

- Easy to operate to for non-specialist, particularly for real-time positioning, as there is no need to locate the mark and prove it reliable.

Jeddah region located between Lat. $20.7^{\circ}-22.3^{\circ} \mathrm{N}$ and Long. $39.0^{\circ}-40.5^{\circ}$ E. It covers a region of about $100 \mathrm{~km} \times 50 \mathrm{~km}$. Jeddah Municipality (JM) established a system of GNSS CORS to provide the GPS users in Jeddah with VRS services to facilitate and improve the surveying applications. The system is currently composed of nine GPS stations distributed to cover the whole area of Jeddah (fig.1) [Jeddah Survey Directorate web, 2012]. Currently, the system enables the users to achieve $\mathrm{cm}$-accuracy of horizontal position with single GPS receiver. The current research introduces the design, establishment and as sessment of Jeddah CORS/VRS network as well as its future developments and plan.

\section{CONCEPT OF VIRTUAL REFERENCE STATION}

The virtual reference station (VRS) is a concept, which helps to reach centimeter-level, or even better accuracy of positioning. It requires use of precise dualfrequency carrier phase observations using a network of reference stations. These observations are usually processed using a differential GNSS algorithm, such as real time kinematic (RTK).

A differential GNSS setup consists of a single reference station from which the raw data (or corrections) are sent to the rover receiver (the user). The user then forms the carrier phase differences (or corrects their raw data) and performs the data 
processing using the differential corrections. GNSS network configuration often makes use of multiple

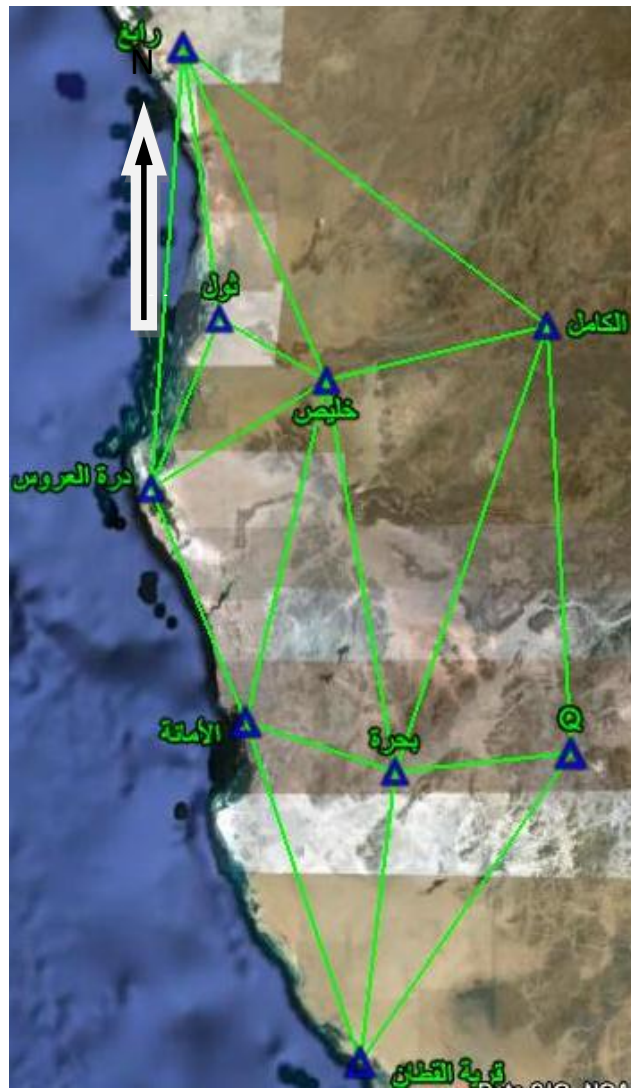

Fig. 1: Current configuration of Jeddah CORS/ VRS.

reference stations. This approach allows a more precise modelling of distance-dependent systematic errors, principally caused by ionospheric and tropospheric refractions, and satellite orbit errors. More specifically, a GNSS network decreases the dependence of the error budget on the distance of nearest antenna [e.g. Gopi et al, 2012].

The network of receivers is linked to a computation centre, and each station contributes its raw data to create network-wide models of the distance-dependent errors. The computation of errors based on the full network's carrier phase measurements involves, the resolution of carrier phase ambiguities and requires knowledge of the reference station positions. The precise positional value of reference station is usually determined as part of the network setup. At the same time, the rover calculates its approximate position and transmits this information to the computation server, for example, via GSM or GPRS using a standard National Marine Electronics Association (NMEA) format. The computation centre generates in real time a virtual reference station at or near the initial rover position. This is done by geometrically translating the pseudorange and carrier phase data from the closest reference station to the virtual location and then adding the interpolated errors from the network error models [ e.g. Ovdii, 2012].

\subsection{Vrs Solution Techniques}

In the CORS/VRS positioning, many techniques can be employed. Among which are; the virtual reference station method (VRS) and the area correction parameter technique (FKP). These methods have differences in the amount of data to be send to the user, the processing strategy, amount of computations at the station, and the type of communications between the network and the rover receiver. The objective is to avoid the distance dependent decrease of accuracy and the equivalent increase of the required time to fix ambiguities.

In order to dominate the distance dependent errors in real-time applications, it is necessary to perform a realtime data analysis using all data from the participating reference stations. In practice, this means that all reference stations need a data link to a computing server where the analysis is executed in quasi realtime, and the distance dependent errors coming from the orbit, the ionosphere, and the troposphere are estimated. This information is then used to correct the results at any given station within the working area. The technique could be named "interconnected reference network", "linked network", or "coupled network".

There are two different solutions for the modelling of distance dependent errors. The first one referred to as Area Corrections Parameters (ACP or FKP). The second one is Virtual Reference System (VRS) [Wübbena, and Willgalis, 2001].

\section{- Area Corrections Parameters (ACP)}

The basic principle for the area correction parameter concept is that, the known coordinates at the reference stations are compared in real-time with the observation results, coming from a data analysis including ambiguity fixing. The residuals $\square \square \square$ at the participating reference stations define a plane in the working area (Fig. 2). The correction for a particular rover position $\square \square \square \square$ can then be determined through a simple interpolation algorithm using the inclination parameters of the correction plane. Through linear combinations of frequencies it is possible to separate the effects into a geometrical model, including tropospheric errors and orbital errors, and into the ionospheric model, including the ionospheric errors [Wübbena et al., 1966].

\section{a. Virtual Reference Station (VRS)}

Within the concept of the virtual reference station the user transmits the approximate coordinates of his position to the analys is server of the CORS. Similar to the ACP concept, a coordinate solution including ambiguity fixing and determination of area correction parameters is generated in the analysis. However, the ACP are not transmitted (Instead, so-called "virtual observations" are generated based on the ACP for the approximate rover position and provided to the user). These virtual observations are valid for a virtual reference station at the approximate rover position, i.e. very close to the real rover position. The user can hence apply close range RTK techniques for his 


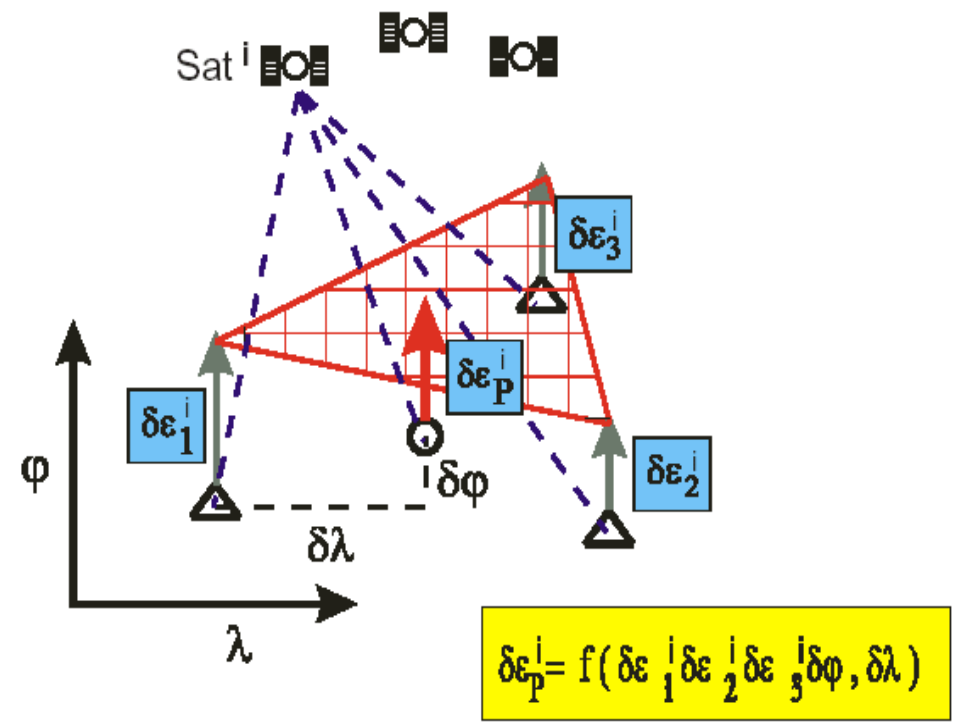

Fig. 2: Explanation of Area Correction parameter Method or CORS RTK.

positioning task [Wübbena et al., 2001].

The VRS correctional data thus yields [Vollath et al. 2000, 2001, 2002a, b and 2003]:

$\operatorname{VRS}^{\mathrm{S}}{ }_{\mathrm{ij}}=\mathrm{CR}_{\mathrm{ij}}^{\mathrm{S}}+\mathrm{f}\left(\mathrm{FKP}_{\mathrm{i}}^{\mathrm{S}}, \Delta \phi_{\mathrm{ij}}, \Delta \lambda_{\mathrm{ij}}, \Delta \mathrm{h}_{\mathrm{ij}}\right)+\Delta \mathrm{T}_{\mathrm{ij}}$

Where $\mathrm{CR}_{\mathrm{ij}}^{\mathrm{S}}$ is the correlated phase observation referred to the reference station computed from the network solution, $f\left(\mathrm{FKP}^{\mathrm{S}}{ }_{\mathrm{i}}, \Delta \phi_{\mathrm{ij}}, \Delta \lambda_{\mathrm{ij}}, \Delta \mathrm{h}_{\mathrm{ij}}\right)$ is the functional relationship dealing with the FKP correction and positions, and $\Delta \mathrm{T}_{\mathrm{ij}}$ represents the difference in troposphere modeling between processing of the network at the reference station and processing for the virtual reference station. The FKP does not contain absolute tropospheric information but gradients of the troposphere. A linear FKP model is used, cantered to a real reference station, and the FKP describes the horizontal gradients for the geometric and ionospheric components in the observation space.

The prediction or interpolation model for state parameters are based on the knowledge about the physical behaviour of the respective parameters. The parameter estimation modules uses dynamic models in a recursive Kalman filter algorithm.

The used state vector $(\rightarrow \vec{X})$ can be given briefly as:

$$
\vec{X}=\left(\mathrm{X}_{\mathrm{i}}, \mathrm{N}_{\mathrm{i}}^{\mathrm{S}}, \delta \mathrm{t}_{\mathrm{i}}, \delta \mathrm{t}^{\mathrm{s}}, \delta \mathrm{O}^{\mathrm{s}}, \delta \mathrm{T}_{\mathrm{i}}^{\mathrm{s}}, \delta \mathrm{I}_{\mathrm{i}}^{\mathrm{s}}, \delta \mathrm{M}_{\mathrm{i}}^{\mathrm{s}}\right)^{\mathrm{T}}(2)
$$

Where $\mathrm{X}_{\mathrm{i}}$ is the vector of unknown, $\delta \mathrm{t}_{\mathrm{i}}$ and $\delta \mathrm{t}^{\mathrm{s}}$ denote the receiver and clock errors, $\delta \mathrm{T}^{\mathrm{S}}{ }_{\mathrm{i}}$ and $\delta \mathrm{I}^{\mathrm{s}}{ }_{\mathrm{i}}$ is the tropospheric and ionospheric errors, $\delta \mathrm{O}^{\mathrm{s}}$ represent orbital erros, and $\delta \mathrm{M}^{\mathrm{s}}{ }_{\mathrm{i}}$ is the multipath error, while super script $\mathrm{T}$ means matrix transpose.

\section{JEDDAH CORS/ VRS ESTABLISHMENT}

Jeddah CORS system is generally composed of GPS base stations, data servers, network communication module and the rover. The base station includes GPS receiver, antenna, and power. Data server consists of both a control and data servers. It is divided into hosted and unmanaged categories; hosted server is provided and maintained by the supplier, non-managed system need to establish an independent data server, the base station and the server is connected directly. Jeddah CORS/ VRS is using the non-managed server. Two servers are connected together; one as a data server and the other as a control. The base stations receivers are Trimble NETRS dual-frequency GPS receiver. For the antenna, the Trimble Zephyr geodetic dual-band antenna with a radome is used. The main software used in processing of Jeddah CORS/ VRS is GPSNET [Trimble, 2007], which uses the VRS method to analyze the data to estimate and represent the state of individual GPS errors in real time. All stations of the network are processed simultaneously using undifferenced observables. Therefore, all error components including the clock errors are estimated.

The first stage of the establishment of Jeddah CORS/ VRS is the design. In this stage, the objectives as well as the limitations are stated. The goal of the design is to fulfil the objectives realizing the limitations in an optimized way. The design includes also, the choice of communication technique between base stations and servers as well as communication for the users in real time.

The objectives of Jeddah CORS/ VRS are:

1. To serve customers dealing with surveying aspects (individual, engineering offices, governmental agencies).

2. Reduces dependency on ground control points. 
3. Increases productivity, decrease cost and minimize labor.

4. Insures an accuracy of $1-2 \mathrm{~cm}$ in Horizontal and 2-5 $\mathrm{cm}$ in height.

5. Provides RTK applications.

6. Facilitates application for the geodynamic and scientific studies.

The base stations choice should consider the following:

1. The base stations locations must be solid;

2. Stay away from strong magnetic fields, and avoid strong electromagnetic interference and multi-path effects;

3. Base station line of sight elevation angle should be more than $10^{\circ}$ for "quasi-clearance", that is to say the horizons over base station must broaden;
4. Be sure to provide the secure, stable, continuous power.

5. Distances between stations are in the range of $50-60 \mathrm{~km}$.

Based on the above goals and limitations, the initial configuration of six stations is implemented (Fig. 3). Trimble NETRS receivers are used as the reference stations. Two computer servers are used; one as a data server and the other for control. The stations are established on the roof of the local governorate offices, as well as the main Jeddah municipality building. This configuration covers about $70 \%$ of the total area of Jeddah. As it is clear from figure 3, the east-west extent of Jeddah is totally covered. The north-south direction shows some uncovered areas, especially in the southem part of Jeddah.

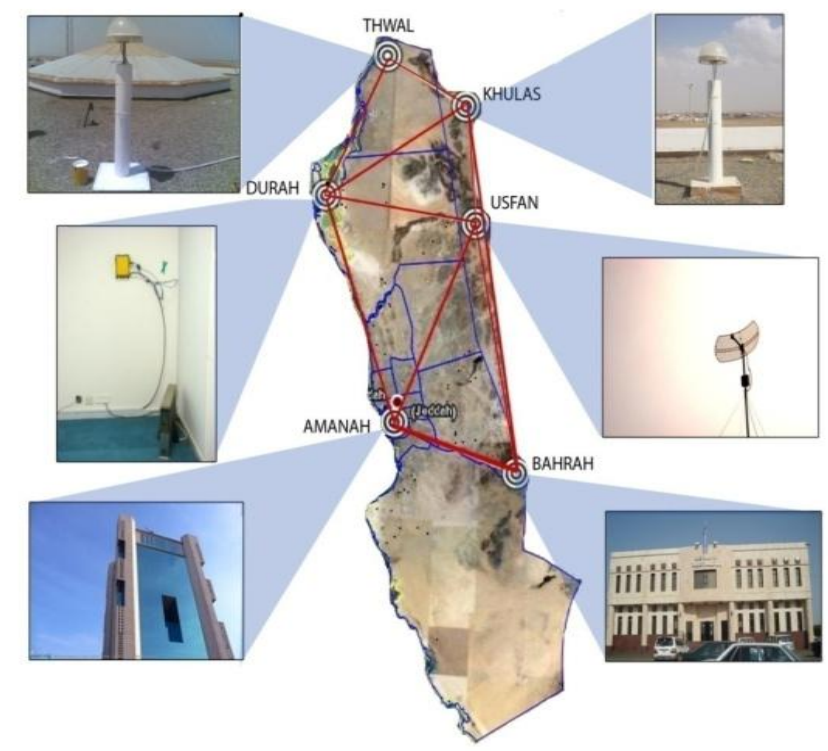

Fig. 3: Original configuration of Jeddah CORS and used monuments.

The selection of a CORS solution and also the number of visible satellites will affect the amount of data which has to be transmitted. The VRS solution broadcasts small quantities of data as the heavy processing takes place within the server, this increases significantly with increasing number of reference stations [Janssen, 2009]. The standard Radio Technical Commission for Maritime Services (RTCM) versions (2.1, 2.3, 3 and 3.1) data format is typically used by all service providers to trans mit the real-time observations and corrections via a mobile phone or wireless internet. Most GNSS receiver manufacturers incorporate RTCM SC-104 standard RTK message types into their RTK systems and this enables interoperability between different receivers.

Latency of the signal at the rover is also a function of the quantity of data being broadcast and the quality of the communications network. The delays that may occur during data transmission between the reference stations and the server, and the server and the data port do not generally affect the solution. The communications network is generally the point at which most latency occurs and accurate VRS solutions are therefore dependent on the existing mobile communications infrastructure available in the region.VRS providers do not specify particular mobile networks and the choice of mobile network rests with the user and is usually based on local knowledge of coverage within an area.

For Jeddah CORS, the communication between the stations and the server is the free band wireless system. The free band wireless system caused a lot of problems due to interference with other users at the heavy business area at north Jeddah. To solve this issue, currently VPN concept is used and it seems to solve most of the interference problems. For real time users, mobile SIMs are used. All the mobile service provider in Jeddah are allowed. These include; Mobily, STC Jawal as well as Zein. Figure (4) shows a schematic diagram of Jeddah CORS communications.

Original reference frame used for Jeddah CORS/VRS is ITRF-2005. The six base stations are connected to the ITRF-2005 using Bernese software V. 5 [Dach et al., 2007]. 13 days of continuous data of the 
CORS stations are solved using a daily session. The overall solution is estimated by stacking the daily normal equations. For this calculation, ITRF-2005 is realized through 10 IGS reference stations (Fig. 4). Table 1 shows the final coordinates of the six CORS stations in ITRF 2005. The accuracy of the solution is shown in table 2.
The adjustment results show that the average horizontal accuracy within ITRF2005 is in the 3-5 mm level, while the height uncertainty is about $13 \mathrm{~mm}$ on average. This is valid for the observation epoch of Jeddah CORS campaign. For the six Jeddah CORS stations the repeatability in the East component is a bit better than for the whole network.

Table 1. ITRF-2005 coor dinates of the Jeddah CORS stations.

\begin{tabular}{|c|c|c|c|}
\hline Station name & $\mathbf{X}$ & $\mathbf{Y}$ & $\mathbf{Z}$ \\
\hline AMANAH & 4603013.4936 & 3749790.2082 & 2323108.4782 \\
\hline BAHRA & 4585712.4962 & 3777016.1103 & 2313306.1913 \\
\hline DORAH- AROS & 4601481.0232 & 3722392.3374 & 2369205.6806 \\
\hline KHOULES & 4571140.9442 & 3746199.4594 & 2390370.5709 \\
\hline THEWAL & 4581738.9795 & 3725160.0566 & 2402680.9500 \\
\hline USFAN & 4577632.2770 & 3753697.5341 & 2366245.6688 \\
\hline
\end{tabular}

Table 2. A verage accuracy estimation for the final solution (all in $\mathbf{m m}$ ).

\begin{tabular}{|c|c|c|c|c|c|}
\hline Accuracy type & Symbol & No.Of stations & $\overline{\mathbf{E}}$ & $\mathbf{N}$ & $\overline{\mathbf{U}}$ \\
\hline formal accuracy & $\sigma_{f}$ & 17 & 0.21 & 0.23 & 0.61 \\
\hline $\begin{array}{l}\text { Repeatability all stations } \\
\text { (Jeddah CORSstations) }\end{array}$ & $\sigma_{\mathrm{r}}$ & $\begin{array}{l}17 \\
(6)\end{array}$ & $\begin{array}{r}1.8 \\
(1.5)\end{array}$ & $\begin{array}{c}3.2 \\
(1.7)\end{array}$ & $\begin{array}{l}6.2 \\
(6)\end{array}$ \\
\hline Fact or (all Stations) & - & - & 8.6 & 13.9 & 10.2 \\
\hline ITRF2005 accuracy & $\overline{\sigma_{\mathrm{i}}}$ & 10 & 1 & 1 & 3 \\
\hline Total Accuracy & $\sigma_{\mathrm{t}}=\sqrt{\sigma_{\mathrm{f}}^{2}+\sigma_{\mathrm{a}}^{2}+\sigma_{\mathrm{i}}^{2}}$ & - & 2.7 & 4.4 & 12.7 \\
\hline
\end{tabular}

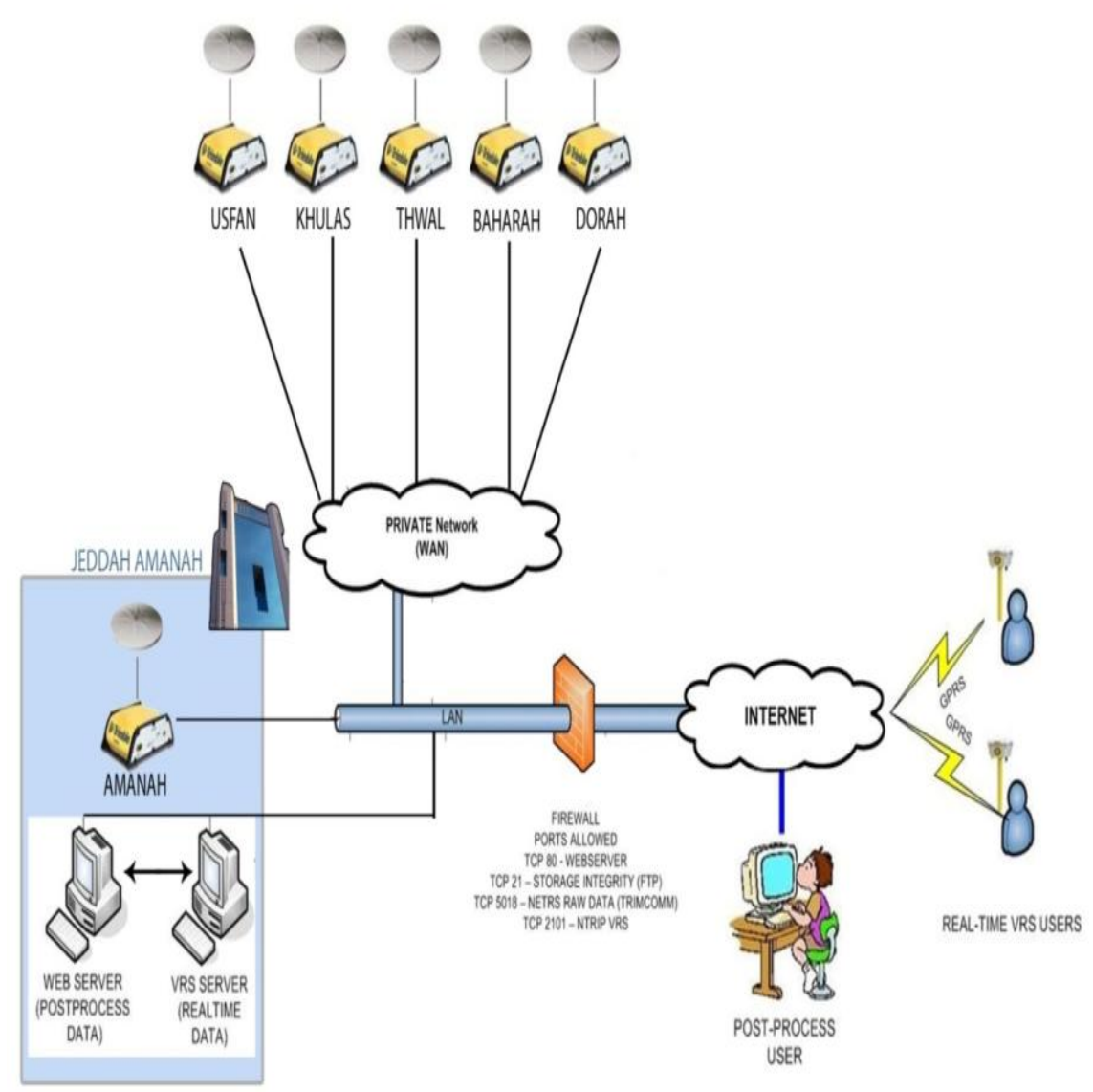

Fig. 4: Schematic diagram showing the Jeddah CORS communications 


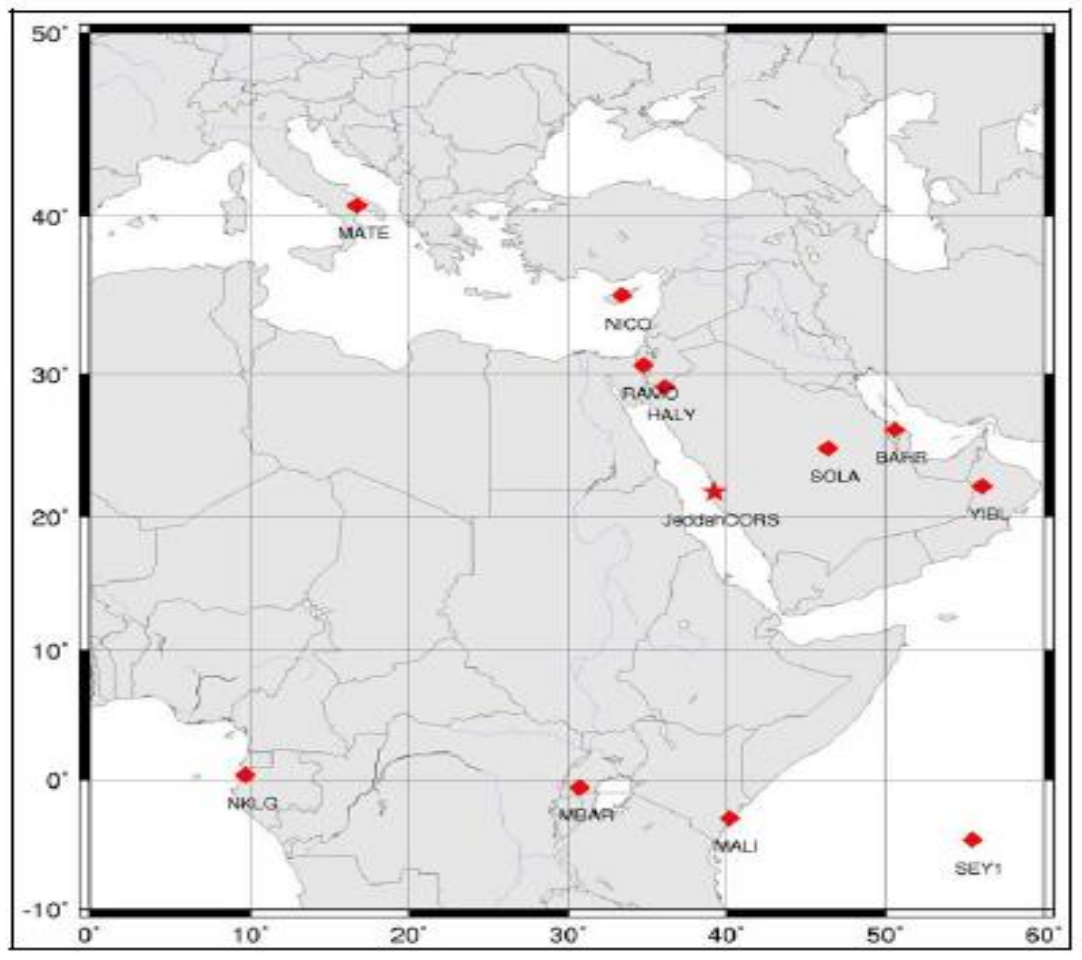

Fig. (5) Network of IGS stations and Jeddah used in Processing.

\section{TESTING OF JEDDAH CORS/ VRS}

Several observations are used to test the accuracy and performance of Jeddah CORS/ VRS. First for real time users, the time to fix is tested. Jeddah CORS/ VRS users use different receivers, including LEICA, Sokkia, TOPCON, and TRIMBLE receivers. All receivers get a fixed solution in about 2 seconds. In some harsh situations, this time might grow to reach 5 seconds (due to some sky obstacle...etc). The average horizontal accuracy of many VRS solution is shown in table 3 . The vertical accuracy is about $2 \mathrm{~cm}$. However, a local geoid model is needed in order to use the VRS directly to estimate the orthometric heights along with their accuracy.

On the other hand, for post processing kinematic, almost the same accuracy level is obtained. To test the static positioning accuracy of Jeddah CORS, data from two projects for establishing GPS ground control points are used. Solution of the control points shows similar accuracy of about $1 \mathrm{~cm}$. The two projects total number is about 38 first order points and 300 second order points [Jeddah control points report, 2009].

Check of the reference station data quality, and the sky plots of multipath are produced. One example is shown in figure 6 . It is clear from figure 6 that the multipath shows very small values. Figure 7 give an example of the number of tracked satellites and the corresponding DOP value for Amanah stations.

Jeddah CORS / VRS started its service on August 2007. It is the $1^{\text {st }}$ CORS network in KSA and it is the $3^{\text {rd }}$ in the Arabic world, after Dubai and Bahrain CORS. Jeddah CORS serves more than 120 users including 100 engineering office and surveying companies as well as researchers. An overview of its usage statistics is given in figure 8 .

Table (3) Obtained VRS solution accuracy (cm)

\begin{tabular}{|c|c|c|c|c|}
\hline \multirow{2}{*}{ Error } & Max. & Min & Average & RMS \\
\cline { 1 - 4 } Direction & 1.5 & 0.4 & 0.8 & 0.04 \\
\hline North & 1.7 & 0.1 & 1 & 0.08 \\
\hline East & 2.1 & 1.2 & 1.6 & 0.6 \\
\hline
\end{tabular}




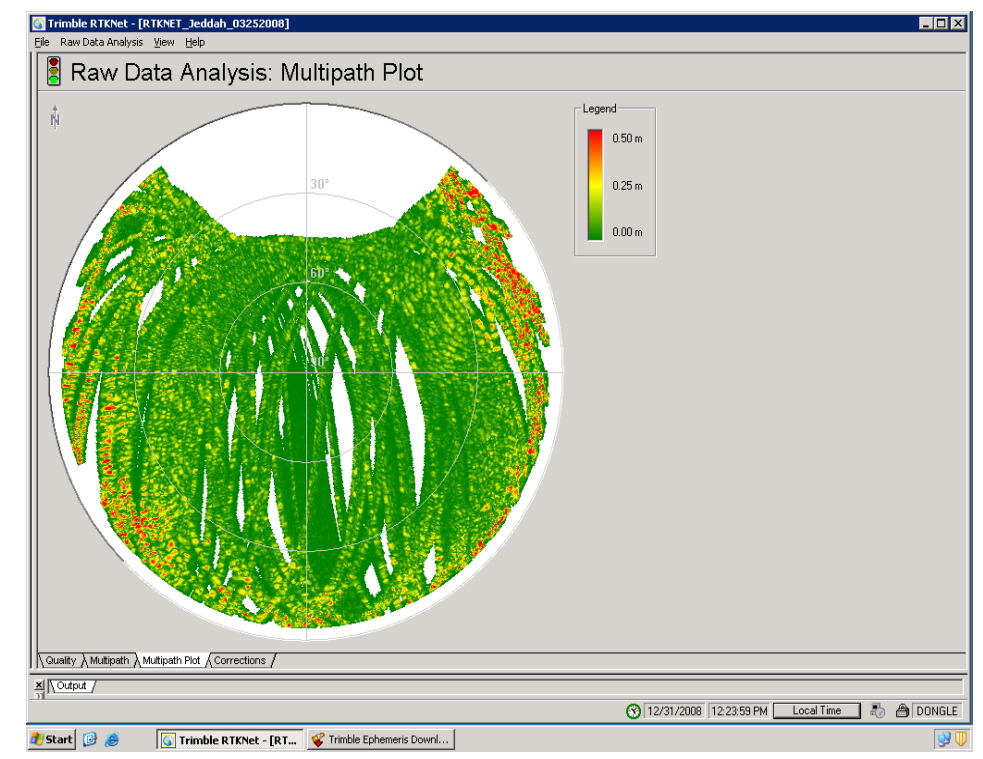

Fig. 6: Example of the Sky pl ots of multipath for Amanah Station.

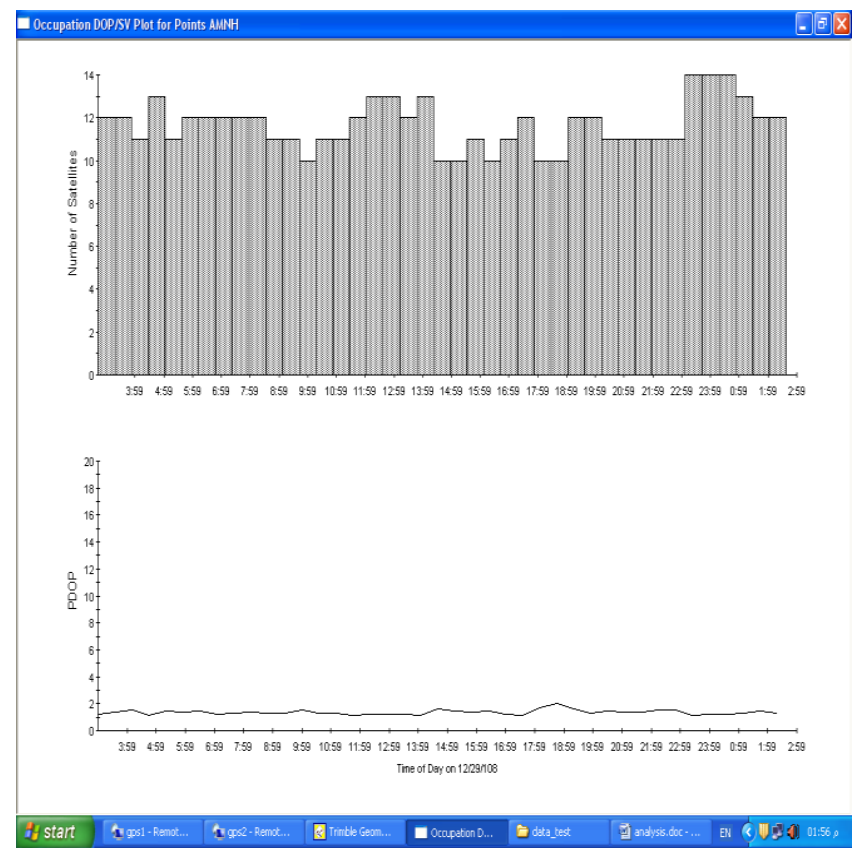

Fig. 7: Example of no. of tracked satellites and DOP value for Amanah Station.

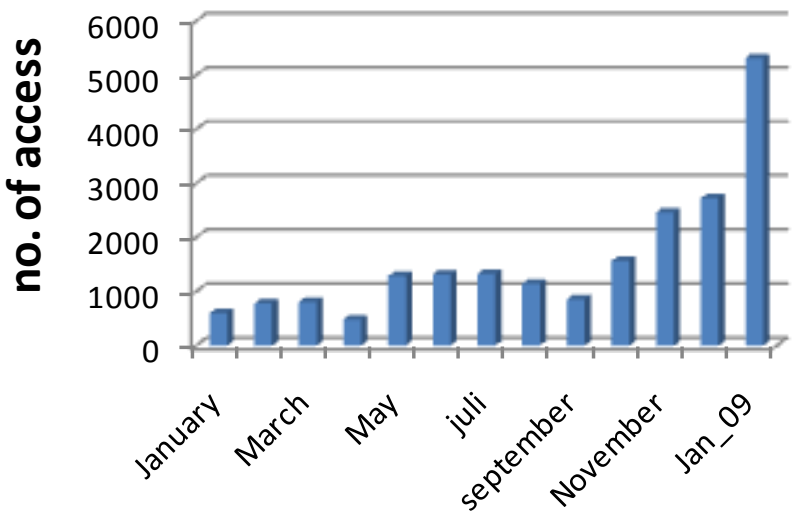

Fig. 8: Number of access of Jeddah CORS/ VRS during year 2008. 


\section{MODERNIZATION OF JEDDAH CORS/ VRS}

Many steps are needed to modernize Jeddah CORS/ VRS to coop with the increasing demand of the users and with the technology advancement. The CORS stations receivers are updated to TRIMBLE NETR5 that tracks GLONASS as well as GPS. NETR5 also track the GPS new L2C signals. Currently a partial replacement of NETR5 receiver is under way with the newest NETR9 receivers. Also, the coverage of the CORS/ VRS is extended to cover almost all Jeddah, as already shown in Figure 1. Now the reference station number is increased to 9 stations. Future extensions to cooperate with the neighbour municipalities are currently under ways.

Future developments of Jeddah CORS/ VRS is being planned now. These developments include providing more statistical data and assessment of the service on a dedicated web page. Possible extension for users in the red sea is also being analysed. The possibility of offering Location Based Services as well is being investigated.

\section{CONCLUSIONS}

Jeddah Municipality (JM) founded a network of GPS reference stations to provide VRS network for different surveying applications. JM provides the users with active control and VRS service to enable them to reach a post processing and a real time $\mathrm{cm}$-accuracy of horizontal position with single GPS receiver. Jeddah CORS/ VRS service about 120 engineering and scientific users.

Assessment of the Jeddah CORS/ VRS network prove that the CORS network works well and provide the service with an accuracy of about 1.5 and $2 \mathrm{~cm}$ for the horizontal and the vertical respectively. A local geoid model is needed to provide the users with orthometric heights. Currently, all the area of Jeddah governorate is coved with the service for both GPS and GLONASS system. Future developments include offering DGPS service for navigation application both in land and sea.

\section{REFERENCES:}

[1] Blick, G., and N. Donnelly (2012), "Should Active Control Networks Replace Passive Control Networks?" FIG Working Week 2012, Rome, Italy, 6-10 May 2012.

[2] Bock, Y., Cecil, H., and Ida, M. (2002). "The California CORS Program", CORS Users Forum, National Geodetic Survey, NOAA/NOS, Silver Spring, Maryland.

[3] Dach, R., Hugentobler, U., Fridez, P., and Meindl, M. (2007) "Bernese GPS Software Version 5.0 User Manual", Astronomical Institute, University of Bern, Switzerland. Free download at http://www.bernese.unibe.ch/docs/DOCU50.pdf. Last visited; August 17, 2007.

[4] Gopi, S., Eman A. Al Falasi, Mustafa M> Baqer, AbdulWaheed Rahmatulla (2012), "Increasing the accuracy, efficiency and coverage of DVRS, by adding three more reference stations to the existing network" FIG Working Week 2012, Rome, Italy, 610 May 2012.

[5] Grejner- Brzezinska, D.A., Kashani, I. Wielgosz, P., Smith, D.A., Spencer, P.S.J., Robertson, D.S., and Mader, G.L. (2007). "Efficiency and reliability of ambiguity resolution in network-based real-time Kinematic GPS.”, J. Surv. Eng., 133(2).

[6] Jeddah control points report (2009), "establishment of $1^{\text {st }}$ and $2^{\text {nd }}$ order ground control points", Internal report, Jeddah surveying directorate, Jeddah, KSA.

[7] Jeddah surveying directorate.(2012), "Website for Jeddah municipality surveying directorate" http://jeddah.gov.sa/Business/Masaha/index.php, visited December 2012.

[8] Janssen, V. (2009) "A Comparison of the VRS and MAC principles for Network RTK", International Global Navigation Satellite Systems Society. IGNSS Symposium, Australia. 1-3, December 2009.

[9] Kinlyside, D. (2006). Sydney Project, Land \& Property Information Division Department of Lands, Bathurst NSW 2795, Australia.

[10] Lachapelle, G, Fortes L.P., Cannon, M.E., Alves, P., Townsend, B. (2001). "RTK Accuracy Enhancements with a Reference Network-Based Approach." The Third International Symposium on Mobile Mapping Technology, Cairo, Egypt, January 3-5.

[11] Ovdii, M., (2012), "Establishment of MOLDPOSa Continuously Operating Reference Stations Network for Moldova", FIG Working Week 2012, Rome, Italy, 6-10 May 2012.

[12] Rizos, C. (2007). "Alternative to current GPSRTK services and some implications for CORS infrastructure and operations," GPS Solution, 11(3).

[13] Trimble, (2007) “ Trimble infrastructure software user manual", Trimble, USA.

[14] Vollath U., A. Deking, H. Landau, C. Pagels, and B. Wagner, (2000), “ Multi-Base RTK Positioning using Virtual Reference Stations", Proceedings of the $13^{\text {th }}$ International Technical Meeting of the Satellite Division of the Institute of Navigation, Salt Lake City, Utah, USA, September, 2000.

[15] Vollath U., A. Deking, H. Landau, and C. Pagels (2001) , "Long Range RTK Positioning using Virtual Reference Stations", Proceedings of the International Symposium on Kinematic Systems in Geodesy, Geomatics and Navigation, Banff, Canada, June, 2001.

[16] Vollath U., H. Landau, and X. Chen (2002a), "Network RTK versus Single Base RTKUnderstanding the Error Characteristics", Proceedings of the $15^{\text {th }}$ International Technical Meeting of the Satellite Division of the Institute of Navigation, Portland, Oregon, USA, September, 2002.

[17] Vollath U., H. Landau, and X. Chen (2002b), "Network RTK - Concept and Performance", Proceedings of the GNSS Symposium, Wuhan, China, November, 2002. 
[18] Vollath Ulrich, Brockmann Elmar, Chen Xiaoming (2003), “Troposphere: Signal or Noise?", Trimble Terras at GmbH.

[19] Wübbena, G., A. Bagge, G. Seeber, V. Bader, P. Hankemeier (1996), "Reducing Distance Dependent Errors for Real-Time Precise DGPS Applications by Establishing Reference Station Networks", Proceedings of the International Technical Meeting, ION GPS-96, Kansas City, Mis souri, 1845-1852.
[20] Wübbena, G., A. Bagge, M. Schmitz (2001), “ RTK Networks based on Geo++ GNSMART Concepts, Implementation, Results", Presented at the International Technical Meeting, ION GPS-01, Salt Lake City, Utah.

[21] Wübbena. G., and Willgalis S (2001), "State Space Approach for Precise Real Time Positioning in GPS Reference Networks", Proceedings of International Symposium on Kinematic Systems in Geodesy, Geomatics and Navigation, KIS-01, Banff, Canada, June 5-8, 2001. 